\title{
Durable, efficient, and economical electronic toilet-training devices for use with retarded children
}

\author{
A. YONOVITZ \\ Speech and Hearing Institute, The University of Texas Health Science Center, \\ Houston, Texas ry025 \\ and \\ ROBERT MICHAELS \\ Mansfield Training School, Mansfield Depot, Connecticut 06251
}

\begin{abstract}
Instrumented behavior observation and modification is typically an expensive process, yet the instruments used are often relatively simple and limited in function. Two sets of electronic devices were constructed to aid in training correct toileting behavior with retarded children. The body-worn alerting unit monitors the residents' elimination as he moves through his environment. This set consists of a moisture detection circuit enclosed in a durable plastic box which is worn by the resident in either a harness or vest. The body-worn alerting unit is connected, via a cord, to underwear which have pliable wires running along their midline. The other set of units monitors elimination on a commode or toilet, and consists of a signaling box containing the moisture-detection circuit and a circular plate which is hung on the toilet or commode. Over 3 years of field testing have shown the units to be very durable and efficient.
\end{abstract}

Probably the most handicapping behavior characteristic of the severely and profoundly retarded is their lack of proper toileting behavior. A review of the literature on toilet training indicated that techniques used with normal children have not been efficient or effective for a retarded population in an institutional setting. Researchers (Azrin \& Foxx, 1971; Foxx \& Azrin, 1973; Van Wagenen, Meyerson, Kerr, \& Mahoney, 1969) have proposed the use of electronic units to monitor a trainee's elimination in both proper and improper locations. This article describes compact battery-operated electronic toilet-training equipment.

Essentially, the toilet-training system is composed of two units: a body-wom alerting device and a unit attached to a commode or toilet to signal elimination. Both units are moisture-detection devices. The economical cost of these units (around $\$ 4$ for the bodyworn unit and $\$ 12$ for the commode monitoring) and the brief construction time required allows the use of these devices in many applicable training programs. Each child wears a moisture-detection circuit contained in a plastic soap box. Special sensing electrodes are sewn into ordinary underwear. Clothing snaps serve as the connectors. As soon as moisture crosses the two electrodes, a loud buzzer sounds. This unit may be used to alert

This equipment was developed under a federal grant (Title I, P.L. 89-313) at the Mansfield Training School, Mansfield, Connecticut. the trainer to the onset of urination. The loud, startling sound typically inhibits elimination. The child is then immediately taken to a commode and in a short while elimination again begins. The beginning of elimination is monitored by another device which signals with a pleasant audible tone. Social and or tangible reinforcement is then administered.

These devices have been constructed for efficiency and durability and have withstood destructive behaviors found in some retarded individuals. The units have been field tested and have been in use for over 3 years. Mechanical modifications have made them extremely reliable. This article is not intended to provide adequate construction details for an inexperienced technician. We have prepared an extremely detailed construction manual giving step by step construction procedures. The manual provides a detailed list of materials and supplies for these devices.'

\section{BODY-WORN ALERTING UNIT}

A schematic diagram of the body-worn alerting unit is shown in Figure 1. The electronic components are mounted on a small printed-circuit board. The alerting buzzer, battery pack (four AA penlight cells), and the printed circuit are then mounted with the connecting wires leading to a jack on the plastic soap box. The connecting cord is fashioned with a plug on one end and with ordinary clothing snaps soldered to the opposite end. 


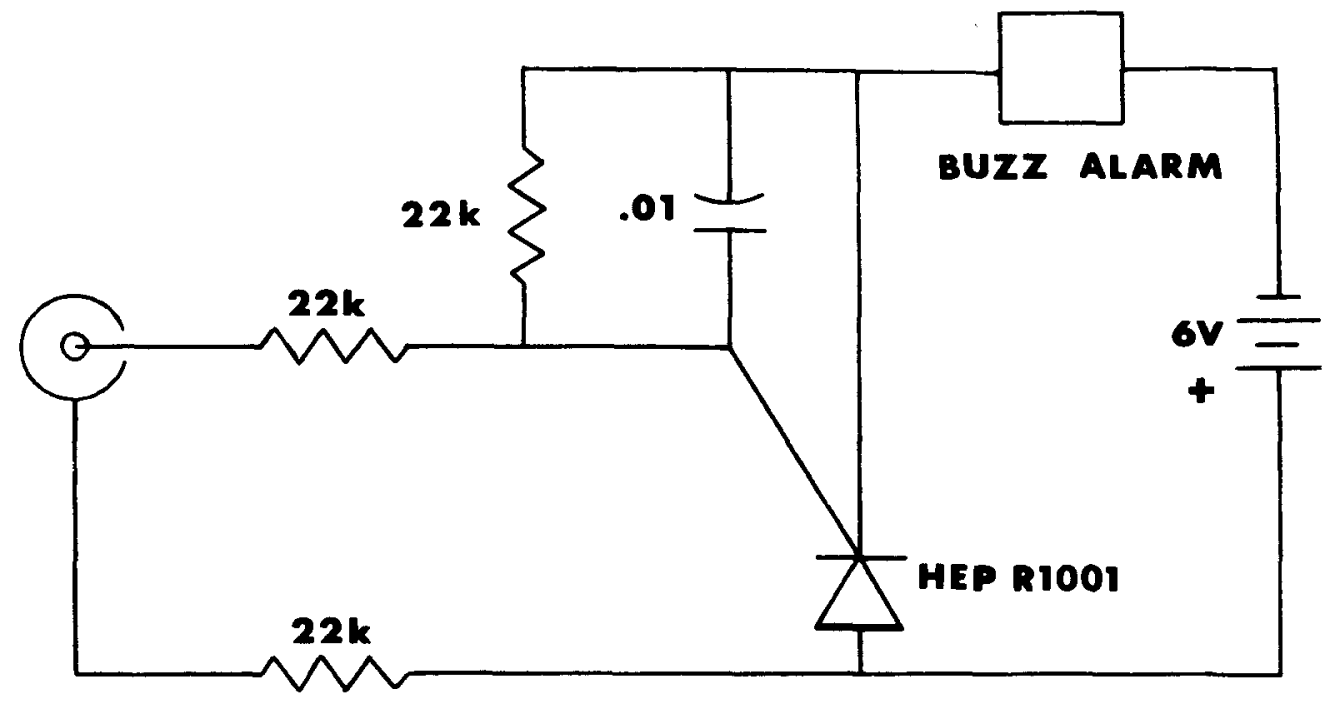

Figure 1. Schematic diagram of the body-worn alerting unit. All resistors are $1 / 2 \mathrm{~W}$. Capacitors are in microfarads. The HEP R1001 is available from Motorola distributors. The buzz alarm is Radio Shack 273-004.

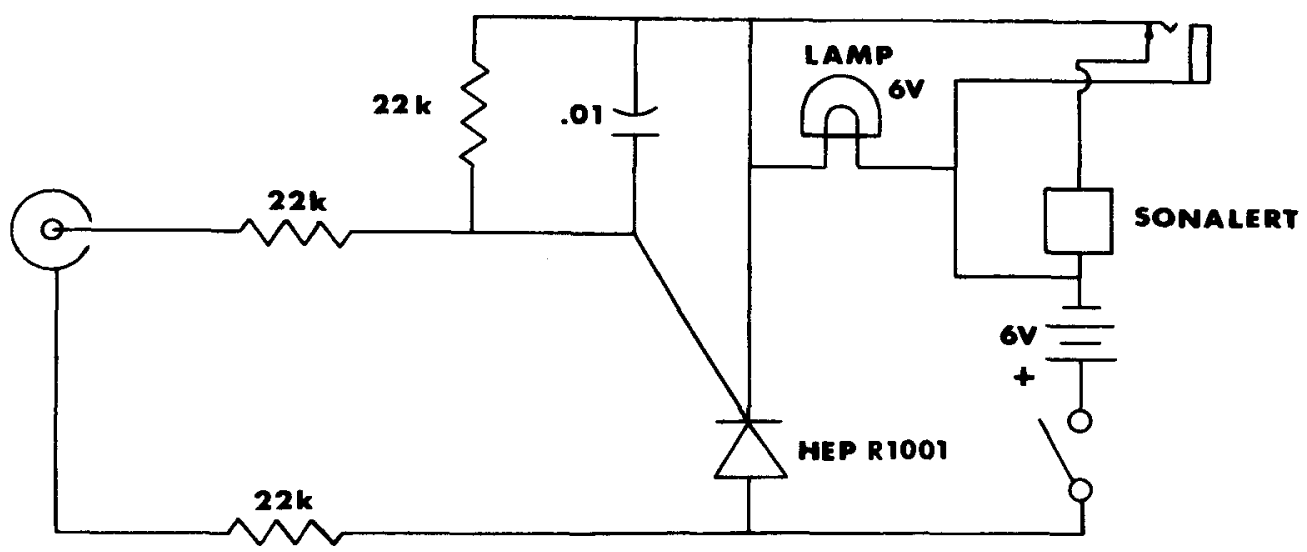

Figure 2. Schematic diagram of the one-channel toilet/commode monitor. All resistors are $1 / 2 \mathrm{~W}$. Capacitors are in microfarads. The HEP R1001 is available from Motorola distributors. The sonalert is Mallory SC628.

\section{SENSITIZED TRAINING PANTS}

The sensitized training pants are fashioned from ordinary underwear. Essentially, two parallel tinsel wires (cloth-like) are sewn within a cotton strip. The wires are separated by a stitch along the center. This strip is then sewn along the midline of the underwear. The wires terminate on female clothing snaps. When the snaps are pressed into the cloth simultaneously, an efficient electrical connection to the sensing wires occurs. This arrangement has proven to be very durable and has withstood daily laundering.

\section{ONE- AND TWO-CHANNEL TOILET/COMMODE MONITOR}

Schematic diagrams of the toilet/commode monitor are shown in Figures 2 and 3. The sonalert device emits a pleasant-sounding $2,900 \cdot \mathrm{Hz}$ pure tone when moisture occurs across the input connections. The light is activated at the same time. With the two-channel monitoring unit, the light indicates the input being activated. Each device also contains an external output connector that can be used to trigger immediate reinforcement such as a token or an $\mathbf{M} \& \mathbf{M}$ candy from a dispensor. This 


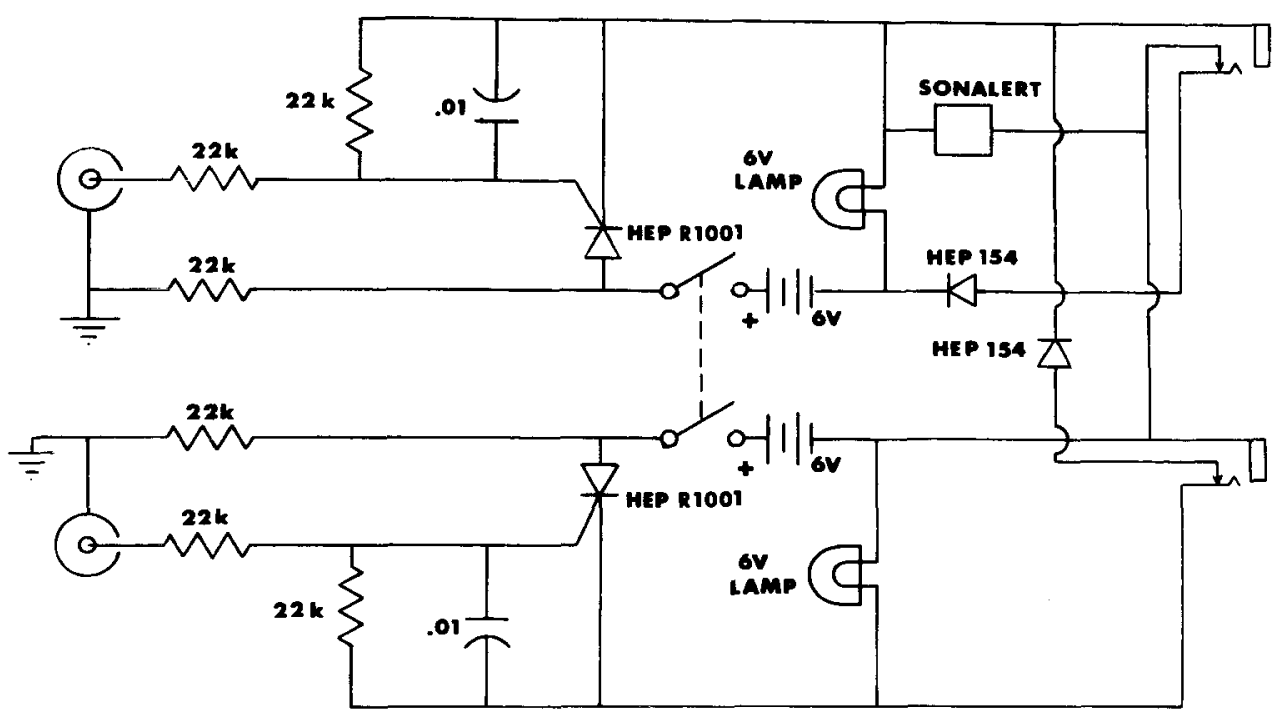

Figure 3. Schematic diagram of the two-channel toilet/commode monitor. All resistors are $1 / 2 \mathrm{~W}$. Capacitors are in microfarads. The HEP R1001 and HEP $154 \mathrm{~s}$ are available from Motorola distributors. The sonalert is Mallory SC628.

output is approximately $6 \mathrm{~V}$ and can supply up to $500 \mathrm{~mA}$ of current.

\section{SENSING PLATE}

The sensing plate is a printed-circuit board etched to yield $1 / 4$-in. copper strips with about $1 / 4$ in. between the strips. Every other strip is connected together to form one of the electrodes, while the same occurs for the other alternating strips. A firm connecting cord attaches the sensing plate to the one- or two-channel toilet/ commode monitors. When moisture contacts any two adjacent strips, the monitor responds with a pleasant tone.

\section{OPERATION}

After a belt or harness has been placed on the child, the alerting unit should be attached. With sensitized training pants on the child and the unit connected, the device is made operational. Experience has shown that the extra expense involved in using quality batteries is repayed by the reduction of down time in the units. Our programs, which involve training children $8 \mathrm{~h}$ daily, have provided about 6 weeks of usable battery time. However, no significant battery drain occurs unless water contacts the sensing wires; thus, the batteries need not be taken out when the unit is not in use.

Operation of the one- and two-channel toilet/ commode monitors are similar electronically to the body-worn alerting unit. When the switch is set to the "on" position, the unit is operational. When water bridges any two strips on the sensing plate, the tone sounds. To stop the tone, the unit must be momentarily switched to "off." In addition, the sensing plate must either be dried or unplugged, or the tone will activate when the device is turned on again. This is essentially a moisture-detection device, so the sensing plate must be thoroughly dried after each occurrence and the signaling unit kept dry.

\section{REFERENCES}

Azrin, N. H., \& Foxx, R. M. A rapid method of toilet training the institutionalized retarded. Journal of Applied Behavior Analysis, 1971, 4, 89-99.

Foxx, R. M., \& AzRIN, N. H. Toilet training the retarded. Champaign, Ill: Research Press, 1973.

VAn Wagenen, R. K., Meyerson, L., KerR, N. J., \& MAHONEY, K. Field trials of a new procedure for toilet training. Journal of Experimental Child Psychology, 1969, 8, 147-159.

\section{NOTE}

1. A copy of the manual may be obtained from Dr. A. Yonovitz. The 116-page detailed manual will be mailed upon receipt of $\$ 2$ to cover the cost of postage and printing. Mailing address: Dr. A. Yonovitz, Speech and Hearing Institute, The University of Texas Health Science Center, 1343 Moursund, Houston, Texas 77025 .

(Accepted for publication April 21, 1977.) 